\title{
Evolution of extreme rainfall events over Indo-Gangetic plain in changing climate during 1901-2010
}

\author{
R BHATLA ${ }^{1,4, *}$, SHRUTI VERMA ${ }^{1,4}$, RITU PANDEY ${ }^{2}$ and A TRIPATHI ${ }^{3}$ \\ ${ }^{1}$ Department of Geophysics, Institute of Science, Banaras Hindu University, Varanasi 221 005, India. \\ ${ }^{2}$ Department of Chemical Engineering, Indian Institute of Technology-Bombay, Mumbai 400 076, India. \\ ${ }^{3}$ Centre for Ocean Atmospheric Sciences and Technology, Amity University, Jaipur 303 002, India. \\ ${ }^{4}$ DST-Mahamana Centre of Excellence in Climate Change Research, Institute of Environment and Sustainable \\ Development, Banaras Hindu University, Varanasi 221 005, India. \\ *Corresponding author. e-mail: rbhatla@bhu.ac.in
}

MS received 11 October 2017; revised 16 November 2018; accepted 5 February 2019; published online 8 May 2019

Due to climate variability and climate change there is an increase in magnitude and frequency of extreme precipitation events. During the last few decades these extreme rainfall events have been increased in global as well as on regional scale. Our climate is very much affected by the changes in frequency of extreme rainfall events. Particularly, variability of extreme rainfall events has been studied over one of the most valuable Indian region i.e. over Indo-Gangetic plain (IGP). Long term trend in extreme events has been analyzed with the help of IMD classification. The classification is considered for moderate rain $\left(2.5^{-}\right.$ $64.4 \mathrm{~mm}$; category I), heavy rain (64.5-124.4 mm; category II) and very heavy rain (124.5 mm or more; category III) and the categorization of rainfall events is based on daily rainfall for the period 1901-2010 during Indian summer monsoon (JJAS). The significant long term trend in frequency of extreme rainfall events is analyzed using the statistical test. Long term trend analysis shows the significant decreasing trend for categories II and III. However, an increasing rainfall frequency is observed for moderate rainfall events (category I) during the considered period. A significant interannual and inter-decadal fluctuation in rainfall frequency and magnitude were observed over IGP. Events of moderate and heavy rainfall increases during the withdrawal period of Indian summer monsoon, which might contribute in several cases of flood in the region of IGP. In term of distribution and contribution of rainfall in agriculture area categories I and II, rainfall events are more important but changes in rainfall pattern may lead to flood and drought risk over IGP. The policy making decision for disaster risk and food security should be based on spatial as well as temporal variability of rainfall pattern over IGP region.

Keywords. IGP; extreme events; decadal; dry and prolonged dry spell; prolonged and short rain event.

\section{Introduction}

Southwest monsoon has a pronounced impact over the Indian subcontinent. Indo-Gangetic belt, which constitutes area about $6,00,000 \mathrm{~km}^{2}$ and the largest section of Indian population and consists of seven meteorological centers Punjab, western and eastern Uttar Pradesh, Bihar, Jharkhand and Gangetic West Bengal. Indo-Gangetic plain, also known as Indus-Ganga plain and north river plain, is drained by three major rivers - Indus, Ganga and Brahmaputra. In the north of this landlocked region lies 
the Himalayan range, which predominantly controls the weather and rainfall of the region. This region has the most population and fertile land in India. The agriculture of this region depends heavily on monsoonal rain and hence any alteration in the rainfall pattern can cause adverse effect on agriculture, health and economy.

The rising temperature of earth due to global warming has resulted in climate change, which is depicted by broad range of global phenomenon like melting of ice caps (a decrease of $13.4 \%$ per decade of arctic ice), glaciers (a decrease of 287.0 billion ton of land ice/year), increase in sea level (3.4 no. of rain event per year), the increase in global temperature $\left(0.8^{\circ} \mathrm{C}\right.$ rise since 1880), the increase in frequency of extreme events like very heavy rainfall, heat and cold wave. Extreme heavy/deficit rainfall events may bring flood and drought-like situation, which have immense adverse impact on human lives and society including health, stability and economy. The spread of diseases and casualties during extreme events, such as heat wave, floods and droughts, increases (Epstein 2005). The summer monsoon rainfall variability and extreme rainfall conditions were investigated on the basis of observational data during 1901-1989 May (2004). Climatology of variability of extreme rainfall events are dependent on the convection associated with low pressure or monsoon depression, mid-tropospheric cyclones, local convection, thunderstorm and other mesoscale phenomena (Dash et al. 2009). A small decreasing trend in mean summer monsoonal rainfall has been found over India (Dash and Hunt 2007; Dash et al. 2007). A significant increasing trend in extreme rainfall events has been observed over west coast and central India using daily data of rainfall during the period 1951-2005 (Pattanaik and Rajeevan 2010).

Based on station and grid point rainfall data, various studies on daily extreme rainfall have been done (Goswami et al. 2006; Rajeevan et al. 2008; Ghosh et al. 2009; Guhathakurta and Menon 2011; Bhatla et al. 2016). Most of the studies done were for the whole country or on the sub-divisional scale and these described the long term trends. Only few studies have been done on regional and local scale such as Saseendran et al. (1995), Prasad and Agrawal (1996), Sinha Ray and Srivastava (2000), Mohapatra et al. (2003), Guhathakurta et al. (2015), Mohanty et al. (2014) and Sonar (2014). The precipitation and temperature extremes over India are changing and the climate of the region is shifting towards wetter and warmer climate (Revadekar 2010). Thapliyal and Kulshrestha (1991), Gadgil (2003) and Sahai et al. (2003) studied the variability of Indian summer monsoon rainfall (ISMR). Various studies have been carried out previously to describe the variations in ISMR over Indo-Gangetic region by Sinha and Jain (1998), Adel (2001, 2002) and Chowdhury and Ward (2004). The duration and intensity per day of rainfall, using gridded $\left(1^{\circ} \times 1^{\circ}\right)$ rainfall data for the period 1951-2004, was observed to study the changes in frequency of rain events in India and it was found that the frequencies of moderate and low rain days have decreased in last half century (Dash et al. 2009). Impact of climate change on regional and some local climate events (Bhatla and Tripathi 2014) is seen during recent past event. Bhatla et al. (2015) examined the rainfall over IGP in relation to El Nino/La Nina. In the present study, our prime objective is to study variability of extreme rainfall events over IGP during the period of 110 years (1901-2010).

\section{Data and methodology}

Using the daily gridded rainfall data with resolution $0.25^{\circ} \times 0.25^{\circ}$ obtained from India Meteorological Department (IMD), rainfall pattern and extreme rainfall events has been studied over the Indo-Gangetic plain for 110 years (1901-2010) as shown in figure 1. Rainfall events have been classified and defined by IMD into various categories (table 1), depending upon rainfall received in a day. These rainfall categories have been further regrouped into four major categories: non-rainy day, categories I, II and III (Bhatla et al. 2016). Non-rainy days have been defined (as per IMD) as days receiving 0 to $2.4 \mathrm{~mm}$ of rainfall. Category I rainfall, which includes the light, moderate and rather heavy rainfall events, has been defined as days receiving rainfall of $2.5-64.4 \mathrm{~mm}$. The category II rainfall is defined as rainfall of $64.5^{-}$ $124.4 \mathrm{~mm}$ in a day and includes of heavy rainfall. Very heavy rainfall and exceptionally heavy rainfall has been included in category III. Category III has been defined as rainfall of $124.5 \mathrm{~mm}$ or more in a day.

In addition to this, the analysis of dry spell, prolonged dry spell, short rain event and prolonged rain events have also been carried out during the period 1901-2010 over the region of study. When a rainfall less than $2.5 \mathrm{~mm}$ /day occurs for a day or 


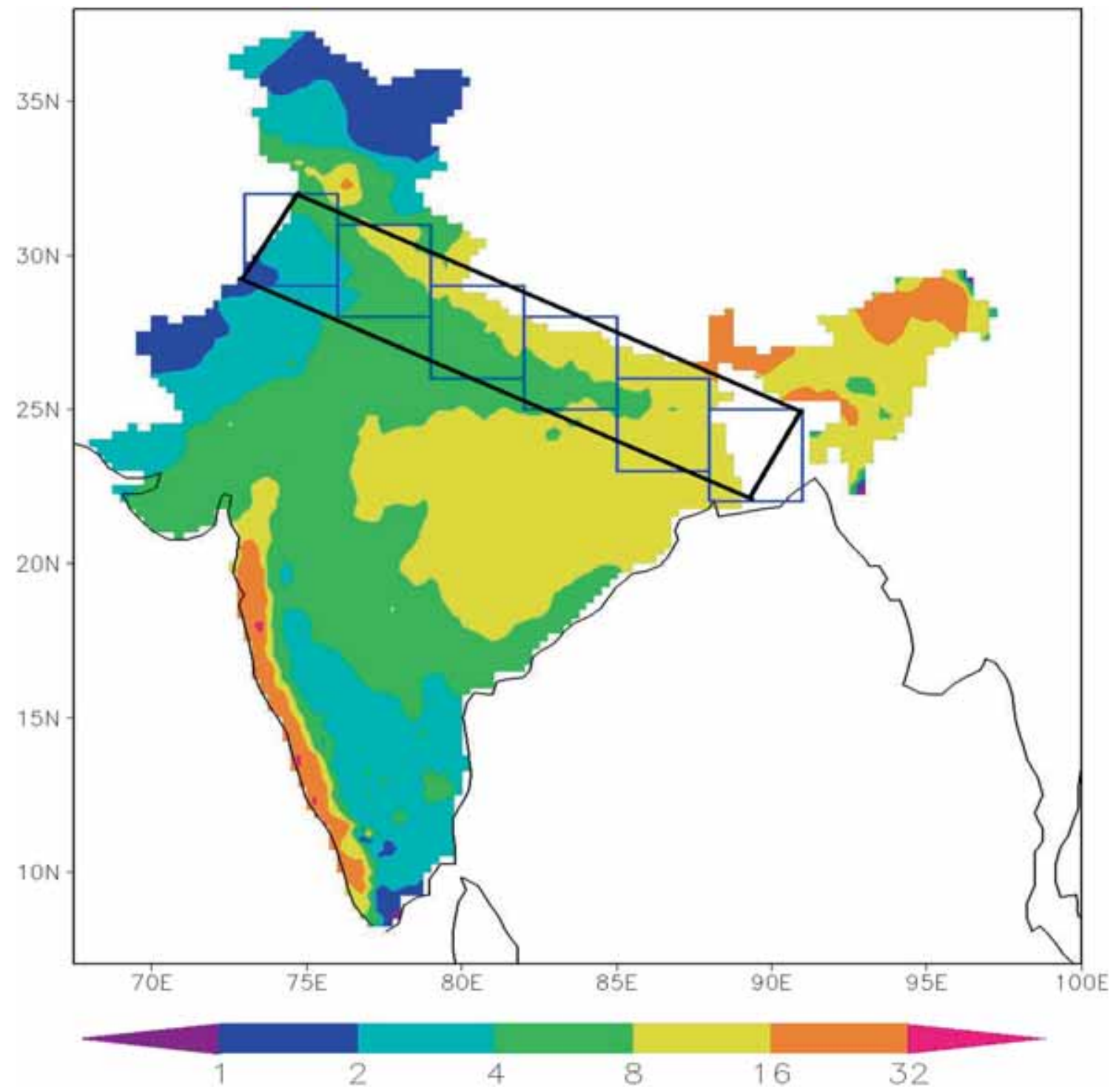

Figure 1. Study region and climatology of monsoon rainfall (mm/day) over Indo Gangetic plain region (black box) during time period of $1901-2010$.

Table 1. Categorization of rainfall events based on daily rainfall.

\begin{tabular}{|c|c|c|c|}
\hline \multicolumn{2}{|c|}{ IMD classification } & \multicolumn{2}{|c|}{ IMD classification regrouped for this study } \\
\hline Rainfall categories & Daily rainfall $(\mathrm{mm})$ & Rainfall categories & Daily rainfall (mm) \\
\hline No rain & 0 & Non rainy day & $0.0-2.4$ \\
\hline Very light rain & $0.1-2.4$ & & \\
\hline Light rain & $2.5-7.5$ & Category I & $2.5-64.4$ \\
\hline Moderate rain & $7.6-35.5$ & & \\
\hline Rather heavy rain & $35.6-64.4$ & & \\
\hline Heavy rain & $64.5-124.4$ & Category II & $64.5-124.4$ \\
\hline Very heavy rain & $124.5-244.4$ & Category III & $124.5 \mathrm{~mm}$ or more \\
\hline Exceptionally heavy rain & $\geq 244.5$ & & \\
\hline
\end{tabular}

for more than one day, it is referred as dry spell. However, if the rainfall $<2.5 \mathrm{~mm} /$ day for 4 days or more occurs the event is defined as prolonged dry spell. Short rain events are those events in which rainfall less than or equal to $2.5 \mathrm{~mm} /$ day occurs for less than four days. When rainfall of $2.5 \mathrm{~mm} /$ day 
or more occurs for more than four days, it is defined as long spell rain event Dash et al. (2009). When a rainfall of 2.5 or more is obtained in a day then the day is said to be rainy day. Frequency of a particular event or category is defined as the number of day for which the event occurs.

Non-parametric Mann-Kendall technique has been used to examine the significance of the rainfall event trend. The Mann-Kendall trend test (Mann 1945; Kendall 1975) is one of the widely used nonparametric tests to detect significant trends in time series. The Mann-Kendall test is applicable to the detection of a monotonic trend in hydrology and climatology.

Letting $X_{1}, X_{2}, \ldots, X_{n}$ be a sequence of measurements over time, Mann proposed to test the null hypothesis, $H_{0}$, that the data come from a population where the random variables are independent and identically distributed. The alternative hypothesis, $H_{1}$, is that the data follow a monotonic trend over time. Under $H_{0}$, the Mann-Kendall test statistic is based on the statistic $S$, which is calculated using the formula

$$
S=\sum_{i=1}^{n-1} \sum_{j=i+1}^{n} \operatorname{sign}\left(X_{j}-X_{i}\right)
$$

where

$$
\operatorname{sign}\left(X_{j}-X_{i}\right)= \begin{cases}+1 & \text { if } X_{j}-X_{i}>0 \\ 0 & \text { if } X_{j}-X_{i}=0 \\ -1 & \text { if } X_{j}-X_{i}<0\end{cases}
$$

Under the hypothesis of independent and randomly distributed random variables, when $n \geq 8$, the $S$ statistic is approximately normally distributed with zero mean and variance i.e. $E(S)=0$ as follows

$$
\sigma^{2}=\frac{n(n-1)(2 n+5)}{18} .
$$

As a consequence, the standardized $Z$ statistics follow a normal standardized distribution

$$
Z=\left\{\begin{array}{ll}
\frac{S-1}{\sigma} & \text { if } S>0 \\
0 & \text { if } S=0 \\
\frac{S+1}{\sigma} & \text { if } S<0
\end{array} .\right.
$$

The hypothesis that there is no trend is rejected when the $Z$ value computed is greater in absolute value than the critical value $Z_{\alpha}$, at a chosen level of significance $\alpha$.

\section{Results and discussion}

By considering intensity of rainfall events it divides into different categories. According to this, rainfall frequency is for three different rainfall categories (I, II and III) over the IGP during the period 1901-2010. The monthly (June, July, August and September) and seasonal (JJAS) trend analysis of frequency of rainfall events is shown in figure 2 . Decadal analysis of rainfall frequency is done as shown in figure 3, which is termed as D1 (19011910), D2 (1911-1920),......, D11 (2001-2010). By giving emphasis on duration of rainfall, trend analysis is studied for dry spell, prolonged dry event, short rain event, and prolonged rain event during the period 1901-2010 as shown in figure 5 .

\subsection{Variability of monthly and seasonal rainfall for different categories during 1901-2010}

Monthly and seasonal trend analysis of category I rainfall over IGP for the period of 1901-2010 is illustrated in figure 2(a-e). Increasing trend of rainfall with the rate of 0.006 no. of rain event per year has been observed in figure 2(a). Figure 2(b) depicts a slight increasing rainfall trend than month of June rainfall. Rainfall trend during month of August and September shows increasing trend instead of the fact September is withdrawal month as shown in figures $2(\mathrm{c})$ and $2(\mathrm{~d})$, respectively. Figure 2(e) illustrates an overall significant increasing trend during seasonal (JJAS) rainfall with the rate of 0.072 no. of rain event per year. The year 1997 shows maximum rainfall frequency in category I (i.e. 97 events) shown in figure 2(e). Rainfall event variability is shown in figure $2(\mathrm{f}-\mathrm{j})$ for category II events during the period 1901-2010 over IGP. Figure 2(f) shows almost constant rainfall trend over IGP during month of July. Slightly decreasing rainfall trend is observed during July and August rainfall for category II rainfall event as shown in figure $2(\mathrm{~g}$ and $\mathrm{h}$ ). Decreasing trend of rainfall continue from June to August but September rainfall for category II event depicts an increasing trend with a rate of 0.01 no. of rain event per year. Overall as we analyze seasonal trend of category II rainfall event, it slightly decreases with a rate of 0.002 no. of rain event per year (figure $2 \mathrm{j}$ ). Category II rainfall events show very less variation and maximum monthly rainfall frequency of 39 and 37 is observed in the year 1950 and 1999, 


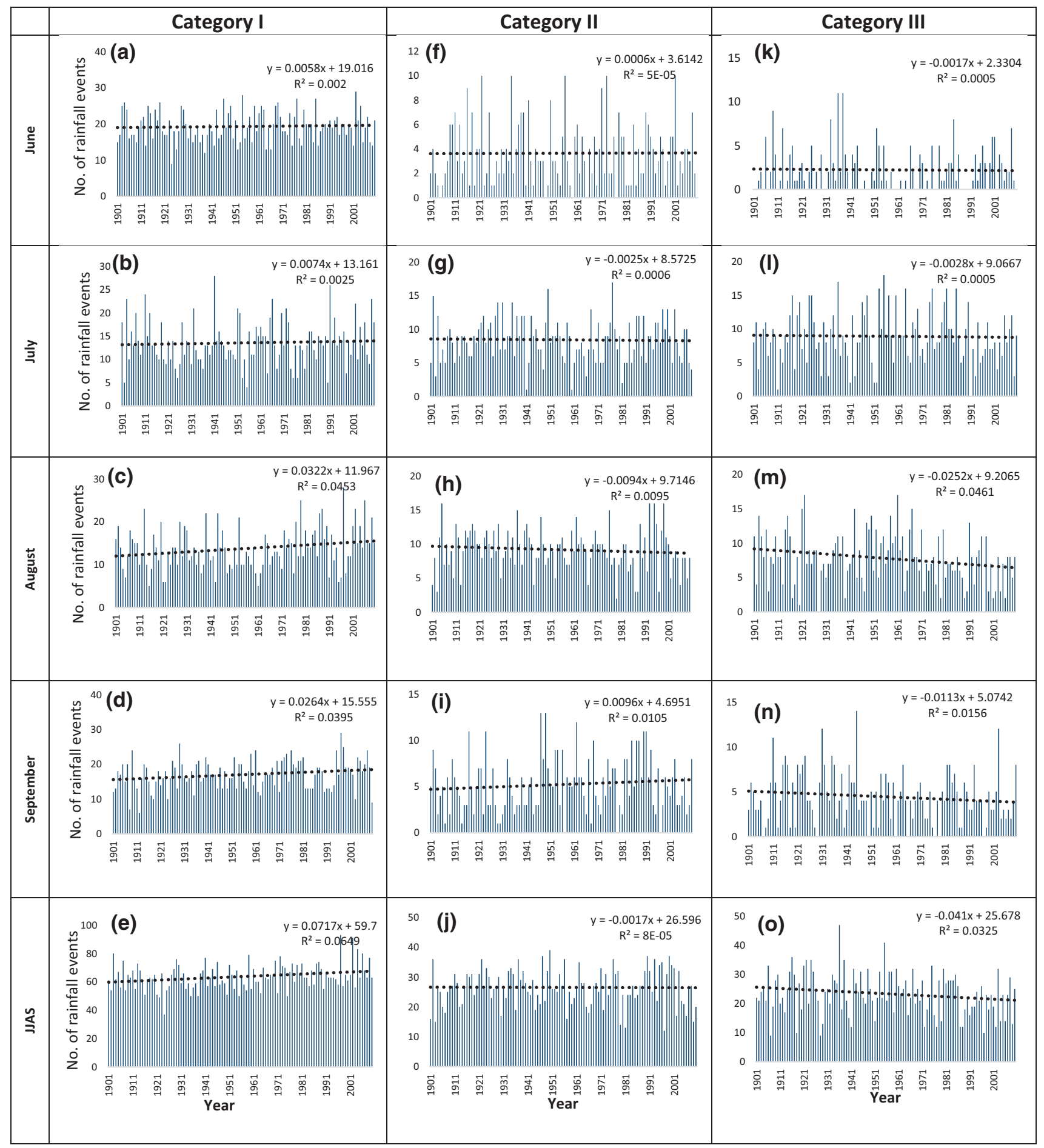

Figure 2. Time series of rainfall frequency of the three categories (I, II and III) during the months June, July, August, September and JJAS over Indo-Gangetic plain.

respectively (figure $2 \mathrm{j}$ ). Monthly and seasonal variability of rainfall events over IGP is discussed in figure 2(k-o) during 1901-2010 for category III. There is considerably less rainfall event than categories I and II rainfall event. Month of July shows continuous trend similar to categories I and II (figure 2k). A considerable decrease in rainfall trend is observed in figure $2(\mathrm{l}$ and $\mathrm{m})$ with a rate of 0.003 and 0.025 no. of rain event per year, respectively. During month of August rainfall trend is significant. Similarly, figure 2(n) shows a decreasing trend of rainfall with a rate of 0.011 no. of 


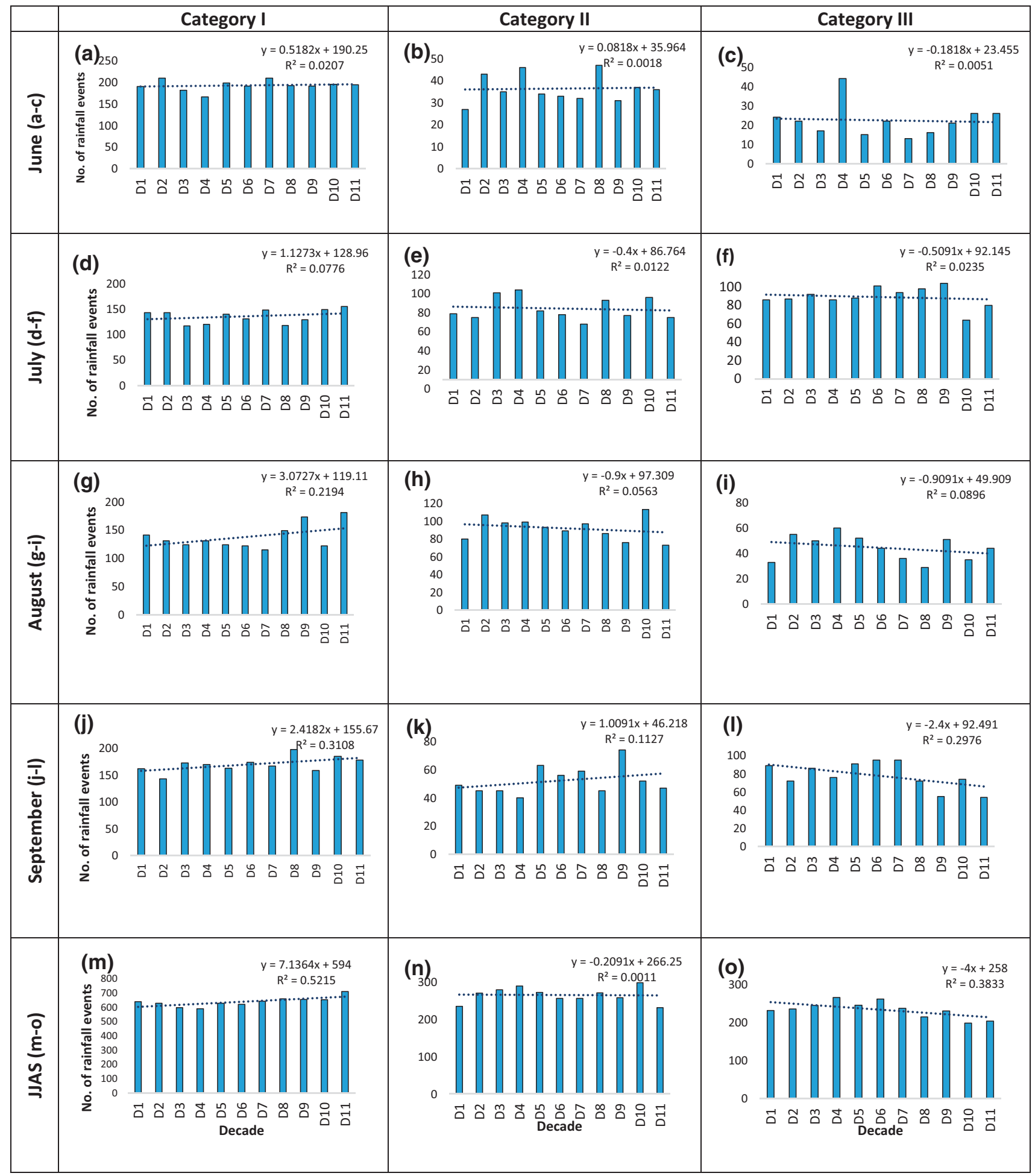

Figure 3. Decadal analysis of rainfall event in different categories over Indo-Gangetic plain (1901-2010).

rain event per year. Seasonal trend of category III rainfall event also depicts significant decreasing trend with a rate of 0.04 no. of rain event per year (figure 2o). Seasonally maximum rainfall event in this category has been observed to be 47 in year 1936 (figure 2o), it is also obvious that the trend is decreasing, but during the recent year such that 2007, 2008 and 2010 maximum rainfall frequency is observed as 23, 29 and 25, respectively. Overall an increasing trend of rainfall is observed for category I rainfall event. This rainfall event shows an insignificant decreasing trend for category II 
rainfall event, but rainfall trend gets a significant decreasing trend over IGP for category III rainfall event.

However, this time series analysis of the three categories of rainfall event in the month of June July, August, September and seasonal does not depict a clear indication of rainfall trend during recent decade, hence for further analysis of 110 years rainfall data on decadal basis i.e. D1, D2, D3,.., D11 is considered for more significant results.

\subsection{Decadal variability of rainfall event for different categories during 1901-2010}

Decadal analysis of rainfall trend for all three categories (I, II, and III) rainfall event over IGP during the period 1901-2010 is shown in figure 3(a-l). Figure $3(\mathrm{a}-\mathrm{c})$ depicts rainfall trend during month of June in three different categories, respectively, for category I rainfall trend increasing with a rate of 0.518 no. of rain event per decade, which is significant at $5 \%$ level. In categories II and III rainfall event, it does not show any significant trend. Overall, figures depict that there are more number of rainfall events that fall under category I events. Figure 3(d) depicts rainfall trend during month of July for category I rainfall event, which are more increasing (1.13 no. of rain event per decade) than June rainfall. Whereas, figure 3(e and f) illustrate that there is a slight decreasing rainfall trend for categories II and III, respectively. These decades wise study during month of July signify that categories II and III rainfall trend decrease but on the other hand for category I rainfall event, it increases over the IGP. An instant and high increasing tendency of category I rainfall event, i.e., 3.1 no. of rain event per decade has been observed in figure $3(\mathrm{~g})$. During recent decade it shows maximum rainfall events mainly during D8, D9 and D11. Figure 3(h and i) shows a decreasing trend are having same rate i.e. 0.9 no. of rain event per decade and during recent decade tendency of categories II and III rainfall event decreasing decadal rainfall trend during month of September shown in figure $3(\mathrm{j}-\mathrm{l})$. A unique and different change is observed for categories I, II and III rainfall event. As September is known as withdrawal month of Indian summer monsoon, it means intensity and frequency of rainfall get reduced but figure $3(\mathrm{j})$ shows decadal significant increasing rainfall trend during month of September with a rate of 2.42 no. of rain event per decade. D8 and D10 are among the highest rainfall decades. But, conversely as showing a decreasing trend for the category II rainfall event for June, July and August. Figure 3(k) shows a significant increasing trend with the rate of 1.01 no. of rain event per decade. During September, category II rainfall event are decreasing in decade D10 and D11. Figure 3(l) depicts a significant decreasing trend with rate of 2.4 no. of rain event per year for category III rainfall event. This 110 years' decadal analysis shows middle of decade shows highest rainfall event mainly for D5, D6 and D7 but rainfall event gets decreasing during recent decade i.e. D8, D9 and D11. Hence decadal variability of monsoonal rainfall reveals that the no. of rainfall events for categories II and III over the Indo-Gangetic plain have been decreasing during the considered period.

\subsection{The maximum rainfall variability during the period 1901-2010}

Maximum rainfall event variability over IGP during month of June, July, August, September and seasonal (JJAS) for period 1901-2010 is illustrated in figure $4(\mathrm{a}-\mathrm{e})$. The maximum rainfall trend is slightly decreasing with a rate of $0.125 \mathrm{~mm} /$ day significant at $5 \%$ level during June over Indo-Gangetic plain (figure 4a). During July maximum rainfall event was showing insignificant increasing trend as shown in figure 4(b). Although maximum variability has been observed during month of June and July. In figure 4(c) decreasing trend of maximum rainfall is observed in month of August, which is significant at $5 \%$ level. During withdrawal month maximum rainfall event shows a decreasing trend with rate of $0.124 \mathrm{~mm} /$ day (figure $4 \mathrm{~d}$ ). Similarly, seasonal analysis of maximum cumulative rainfall during JJAS showing increasing trend (significant at 5\%) has been observed over IGP region (figure 4e) in recent decade 2001-2010. The maximum rainfall is attained in the year 2010, i.e., $920.66 \mathrm{~mm}$.

\subsection{Decade-wise analysis of monthly and seasonal rainfall}

The decadal variation of rainfall for categories I, II and III events over IGP on monthly and seasonal scale are shown in table 2 . The category I rainfall event in the month of June shows increasing trend in all the decades during 1911-1980. The maximum increasing trend for category I rainfall events in the month of June is observed during 


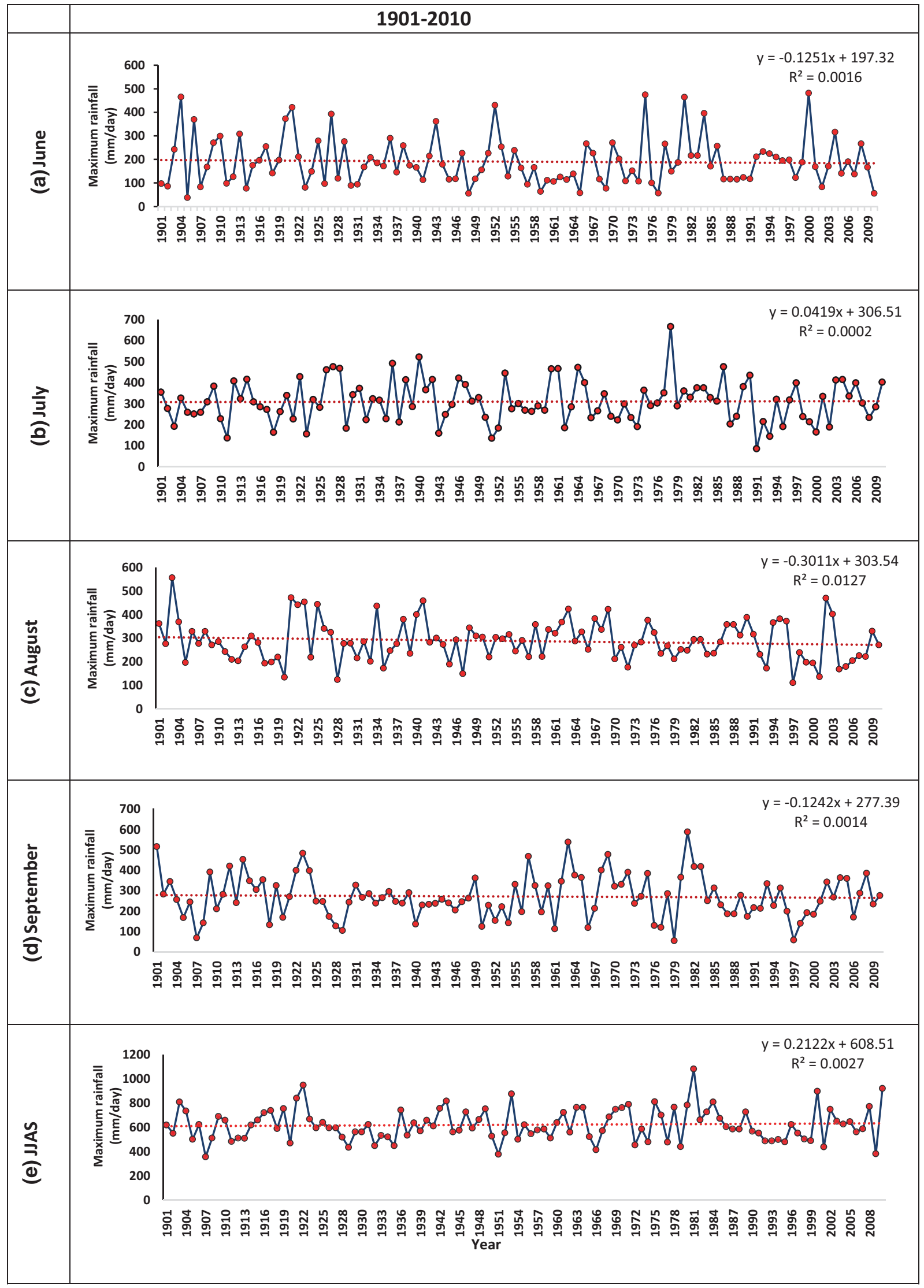

Figure 4. Maximum rainfall trend during June, July, August, September and seasonal (JJAS) over IGP for the period of 1901-2010. 
Table 2. Decadal analysis of category I, category II and category III rainfall during summer monsoon months (June, July, August and September) and season over Indo-Gangetic plain during the period 1901-2010.

\begin{tabular}{|c|c|c|c|c|c|c|c|c|c|c|c|c|c|c|c|}
\hline \multirow[b]{2}{*}{ Decade } & \multicolumn{5}{|c|}{ Category I } & \multicolumn{5}{|c|}{ Category II } & \multicolumn{5}{|c|}{ Category III } \\
\hline & Jun & Jul & Aug & Sep & JJAS & Jun & Jul & Aug & Sep & JJAS & Jun & Jul & Aug & Sep & JJAS \\
\hline D1 & -0.32 & -0.13 & 0.03 & $0.38 *$ & -0.04 & 0.36 & 0.02 & 0.15 & -0.18 & 0.35 & $0.63 *$ & 0.09 & -0.18 & -0.18 & 0.36 \\
\hline D2 & 0.15 & $-1.15 *$ & $0.38 *$ & 0.28 & -0.33 & -0.20 & 0.10 & 0.20 & 0.30 & 0.13 & 0.06 & $1.02 *$ & $-0.58 *$ & $-0.47 *$ & 0.01 \\
\hline D3 & $0.72 *$ & 0.23 & $1.08 *$ & $0.79 *$ & $0.38 *$ & -0.33 & $-0.67 *$ & -0.13 & $-0.62 *$ & $-1.16 *$ & -0.07 & -0.16 & -1.10 & $-0.73 *$ & $-2.06 *$ \\
\hline D4 & 0.02 & -0.13 & 0.04 & $0.44 *$ & 0.37 & 0.13 & 0.11 & 0.18 & -0.04 & $0.38 *$ & 0.33 & 0.02 & -0.05 & 0.72 & -0.41 \\
\hline D5 & $0.44 *$ & $-1.29 *$ & -0.25 & $-0.39 *$ & $-1.49 *$ & -0.13 & $0.78 *$ & -0.26 & $0.82 *$ & $1.20 *$ & -0.22 & $0.51 *$ & $0.43 *$ & $-0.50 *$ & 0.22 \\
\hline D6 & 0.25 & -0.21 & $-0.44 *$ & -0.07 & $-0.47 *$ & 0.02 & 0.05 & 0.05 & -0.22 & $-0.60 *$ & $-0.48 *$ & $0.66 *$ & $0.42 *$ & 0.22 & $0.81 *$ \\
\hline D7 & 0.12 & -0.09 & $0.56 *$ & 0.20 & $0.79 *$ & $-0.46 *$ & -0.20 & -0.20 & -0.32 & $-0.52 *$ & 0.22 & -0.06 & $-0.48 *$ & 0.08 & -0.23 \\
\hline D8 & 0.25 & $-0.80 *$ & $0.43 *$ & $0.40 *$ & 0.28 & -0.20 & $-0.56 *$ & $-0.56 *$ & -0.02 & $0.49 *$ & 0.02 & $0.47 *$ & 0.05 & -0.22 & 0.32 \\
\hline D9 & -0.11 & $-0.50 *$ & $0.47 *$ & -0.02 & -0.16 & $0.50 *$ & -0.13 & 0.13 & $-0.55 *$ & $1.75 *$ & $-0.45 *$ & -0.33 & -0.36 & -0.35 & $-1.49 *$ \\
\hline D10 & -0.21 & $-1.13 *$ & 0.23 & $1.21 *$ & 0.09 & 0.03 & 0.18 & 0.18 & $-0.53 *$ & 0.29 & 0.34 & $0.56 *$ & $0.46 *$ & -0.20 & 0.24 \\
\hline D11 & $-0.47 *$ & 0.15 & -0.31 & -0.04 & $-0.66 *$ & -0.37 & -0.15 & -0.15 & -0.03 & $-0.88 *$ & -0.21 & 0.18 & $0.47 *$ & -0.06 & $0.39 *$ \\
\hline
\end{tabular}

*Indicating $5 \%$ level of significance.

D3. The category I rainfall event shows continuous decreasing trend in the last three decades during 1980-2010. The last decade, 2000-2010, shows the highest decreasing trend in the category I rainfall frequency (with the rate of 0.467 no. of rain event per decade). In the July month, category I rainfall shows a decreasing trend in all the decades from 1901-2000 but it has an increasing trend in the last decade from 2001-2010 (with a rate of 0.152 no. of rain event per decade). The decreasing trend in category I rainfall frequency, in the month of July, is highest during 1911-1920, decreasing at a rate of 1.152 no. of rain event per decade. In the month of August there is increasing rainfall frequency trend in category I rainfall in the first four decades, from 1901-1940. The next two decades, from 1941-1960, show decreasing trend. However, the next four decades 1961-2000, shows an increasing trend, the increasing trend being highest during the 1961-1970 (with a rate of 0.564). However, during the last decade the rainfall events of category I in August month show decreasing trend, with a rate of 0.309 no. of rain event per decade. The category I rainfall events in the month of September show increasing trend during the first four decades from 1901-1940 and the increase being highest during D3 (1921-1930). In the next decades, the rainfall events do not have some regular variations and decreasing trend in the last decade (with a rate of 0.036 no. of rain event per decade). In the last decade, category I rainfall shows decreasing trend in all the months except where it is increasing (with a rate of 0.152 no. of rain event per decade). The decreasing trend in category I rainfall is highest (decreasing with a rate of 0.467 no. of rain event per decade) in the month of June during 2001-2010. The decadal analysis of category I rainfall of the season during 1901-2010, do not show any regular pattern and the rainfall events during the last decade show a decreasing pattern (with the rate of 0.661 no. of rain event per decade).

Similarly, decade wise monthly and seasonal rainfall trend analysis of category II rainfall events is represented in table 2 . In the month of June, no regular pattern in the category II rainfall is observed. The category II rainfall in last decade (2001-2010) shows a decreasing trend, with rate of 0.36 no. of rain event per decade. The category II rainfall events in the month of July show increasing trend in the first six decades, from 1901-1960 with the exception of D3 (1921-1930), where it is decreasing (with rate of 0.67 no. of rain event per decade). However, in the next five decades the rainfall frequency shows a decreasing trend and the category III rainfall events show a decreasing trend at a rate of 0.15 no. of rain event per decade. The month of August shows no definite pattern in category II rainfall events however, in the last decade (D11), there is decreasing trend with the rate of 0.152 no. of rain event per decade. The month of September shows decreasing rainfall frequency trend for most of the decades and the variation with a rate of 0.03 no. of rain event per decade), in the last decade is not significant. The seasonal rainfall events of category II do not show any regular pattern but the last decade (2001-2010) show decreasing trend, decreases with a rate of 0.88 no. of rain event per decade. The decreasing rainfall trend of category II is being found highest (with 
rate of 1.16) during the decade 1921-1930. The increasing trend of category II rainfall events is highest during the D9 (1981-1990) decade, increasing trend of 1.76 no. of rain event per decade. The category II rainfall in the last decade shows decreasing trend during all the four months and the decreasing trend is highest during the month of June. It is observed from the table that category II rainfall events do not show any regular pattern over the Indo-Gangetic plain during the period 1901-2010. Rainfall event variation during month of September on decadal analysis represents a decreasing trend of category I rainfall over the years (1901-2010). The decadal analysis of category III rainfall of the months and season over the Indo-Gangetic region is shown in table 2. In the month of June, the category III rainfall frequency shows no regular pattern during the period (1901-2010). The increasing trend of category III rainfall is being highest during 1901-1910, with a rate of 0.630 no. of rain event per decade. However, the highest decreasing trend, with a rate of 0.485 no. of rain event per decade, in the month of June has been observed during 1951-1960. However, the month of July shows increasing trend in category III rainfall during most decades, the highest increasing trend being, with the rate of 1.024 no. of rain event per decade, during decade 1911-1920. During the last decade (2001-2010) an increasing rainfall frequency trend, with a rate of 0.182 no. of rain event per decade, is observed. In the month of August, the first four decades, during 1901-1940, decreasing trend in category III rainfall frequency is observed and the maximum decreasing trend is observed, with a rate of 1.103 no. of rain event per decade, is observed during the D3 decade. From 1941-2010 no regular pattern in rainfall trend for rain greater than 124.5 no. of rain event per decade, is observed. However, the last decade (2001-2010) shows increasing trend in category III rainfall events in the month of August (with a rate of 0.473 no. of rain event per decade). The month of September shows decreasing trend in category III rainfall frequency during most of the decades and the last four decades (1971-2010) show continuous decreasing trend.

However, the variation in category III rainfall during last decade does not show significant decreasing trend of 0.061 no. of rain event per decade in the month of September. The seasonal analysis of category III rainfall during most of the decades show increasing trend during most of the decades and the highest increasing trend is present during 1951-1960 (with a rate 0.812 no. of rain event per decade). In the last decade (20012010) an increasing trend is found in category III rainfall frequency, with a rate of 0.388 no. of rain event per decade. In the last decade (2001-2010), category III rainfall shows an increasing trend in July and August months and a decreasing trend in June and September month although the decreasing trend in September is not significant.

\subsection{Analysis of dry spell, prolonged dry spell, short rain event and prolonged rain event during 1901-2010 over IGP}

Frequency of dry spell, prolonged dry spell, short rain events and prolonged rain events over the Indo-Gangetic plain during the period 1901-2010 is represented in figure $5(\mathrm{a}-\mathrm{d})$. The short rain events (rainfall with intensity $\geq 2.5 \mathrm{~mm}$ /day for less than 4 consecutive days), prolonged rain events (rainfall with intensity $\geq 2.5 \mathrm{~mm} /$ day for more than 4 consecutive days), dry spell (rainfall $<2.5 \mathrm{~mm} /$ day for one day or more than one day consecutively) and prolonged dry spell (rainfall $<2.5 \mathrm{~mm} /$ day for more than or equal to 4 days continuously) of which trend analysis are presented in figure $5(\mathrm{a}-\mathrm{d})$, respectively. The frequency of dry spell rain events does not show significant trend over the Indo-Gangetic plain during the period 1901-2010 (figure 5a). Thus, it is clear that dry spell rain events have remained constant during the considered period. The prolonged dry spell frequency shows slight decreasing trend (with the rate of 0.004 rain event/year) during the period 1901-2010 (figure 5b). The short rain events over the Indo-Gangetic region also show very minute decreasing trend (with the rate of 0.005 rain event per year) during the considered period. The prolonged rain events show similar kind of decreasing trend (with the rate of 0.005 rain events/year) over the Indo-Gangetic region during the period 1901-2010. Thus, it is clear that none of the four spells show considerable variation over the Indo-Gangetic plane during the period 1901-2010.

\subsection{Decadal analysis of dry spell, prolonged dry spell, short rain events and prolonged rain events during 1901-2010}

Table 3 shows the decadal analysis of the four categorized spells- dry spell, prolonged dry spell, short rain spell and prolonged rain spell over 


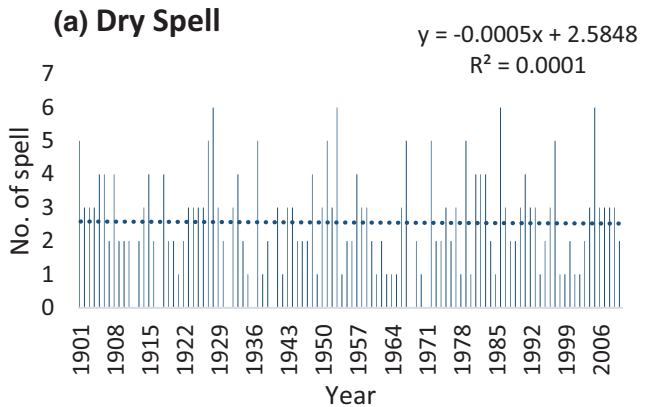

(b) Prolonged Dry Spell

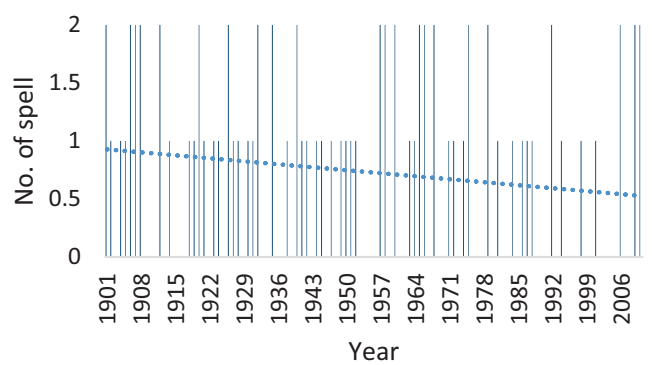

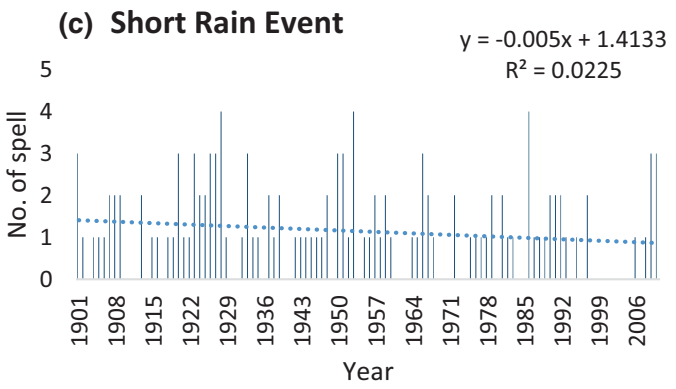

(d) Prolonged Rain Event $\quad \begin{aligned} y=-0.0049 x+2.6108 \\ R^{2}=0.0259\end{aligned}$

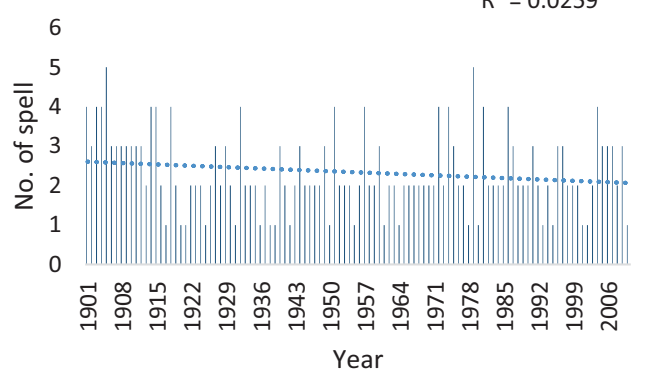

Figure 5. Time series of frequency of (a) dry spell, (b) prolonged dry spell, (c) short rain event, (d) prolonged rain event over the Indo-Gangetic plain.

Table 3. Decadal analysis of dry spell, prolonged dry spell, short rain event and prolonged rain event over Indo-Gangetic Plain during the period 1901-2010.

\begin{tabular}{lcccc}
\hline Decades & Dry spell & $\begin{array}{c}\text { Prolonged } \\
\text { dry spell }\end{array}$ & $\begin{array}{c}\text { Short } \\
\text { event }\end{array}$ & $\begin{array}{r}\text { Prolonged } \\
\text { rain event }\end{array}$ \\
\hline D1 & 32 & 11 & 13 & 35 \\
D2 & 21 & 7 & 9 & 26 \\
D3 & 31 & 8 & 20 & 20 \\
D4 & 18 & 8 & 11 & 19 \\
D5 & 24 & 7 & 11 & 20 \\
D6 & 31 & 8 & 16 & 24 \\
D7 & 17 & 7 & 8 & 18 \\
D8 & 24 & 5 & 8 & 26 \\
D9 & 31 & 4 & 13 & 25 \\
D10 & 25 & 7 & 8 & 21 \\
D11 & 27 & & 8 & 23 \\
\hline
\end{tabular}

Indo-Gangetic region during the period 1901-2010. The table represents decadal analysis of number of four rain spells. The number of dry spell and prolonged rain event constitute maximum number of rain spell among all four spell. The variability of dry spell over all decades is maximum. Decade D3, D6 and D9 shows maximum no. of dry spell and short rain event. During recent decade it also shows increasing trend for the dry spell. Prolonged dry spell shows significant decreasing trend of the rain spell i.e. 0.38 spell/ decade. Short rain event is also depicting a decreasing trend with a slope of 0.54 spell/decade. Number of spell of prolonged rain event over decades showed decreasing trend ( 0.48 spell/decade). The last four decades (1971-2010) show increased number of dry spell with the maximum of 31 during the period 1981-1990. The frequency of prolonged dry spell during recent decades show decrease in number of events over Indo-Gangetic Plain. The last three decades (1981-2010) show minimum frequencies during the overall period (1901-2010), with a minimum of 5 prolonged dry spells during the decade 1981-1990. In the last decade (2001-2010) the frequency of prolonged dry spell is 7 over the Indo-Gangetic plain. The short rain spell shows 
decrease in decadal frequency during the period 1901-2010. The maximum frequency for short rain events is 20, observed during 1921-1930 and minimum frequency of 8 is observed during the last two decades (1991-2010). However, the frequency of prolonged rain event does not show any regular pattern over the Indo-Gangetic plain during the considered period. The maximum frequency for prolonged rain event is 35, observed during 1901-1910 and the minimum frequency of 18 for the same is observed during the decade 1961-1970. During the recent decade (2001-2010) frequency of prolonged rain event is 23 over the Indo-Gangetic region.

\subsection{Possible cause of variability of rainfall events over IGP}

Important synoptic system associated with heavy monsoon rainfall over IGP is monsoon storms/ depressions, low pressure area (surface and/or upper air), seasonal monsoon trough, north-south oriented trough in monsoon westerlies and east/west oriented trough (other than seasonal monsoon trough) mentioned by Srinivasan et al. (1972). Although our study is concentrated to the variability in different categorized rainfall events so that categories II and III rainfall event show decreasing trend which can be explained by a number of possible mechanisms, viz., westward shifting of rainfall, aerosol effect, land use change, sea surface temperature changes, and global changes (Roxy et al. 2015). The westward shift in rainfall activities and severe rainstorms over the western IGP region and declining trend over the central and eastern IGP region is results of the earlier studies (Singh et al. 1992a,b). Jones et al. (1986) suggested that the changes in rainfall and arid area were a consequence of the spatial changes in Indian summer monsoon circulation characterized by strengthening of Arabian sea branch and weakening of Bay of Bengal branch. Climatologically, eastern part of IGP received monsoonal rainfall predominantly from Bay of Bengal (BoB) branch of ISM. Hence, the weakening of wind strength over BoB (Dash et al. 2009) might be the major cause behind the decreasing trend of heavy rainfall. Aerosol negative forcing (cooling) plays an important role in weakening of monsoonal circulation and decreasing precipitation over IGP by reducing the land sea temperature contrast (Sanap et al. 2015). However, increasing trend of moderate rain event might be due to increased mesoscale convection activities and rising rainfall trend in western IGP region during SW monsoon.

The total precipitation has been decreasing over eastern Gangetic plain and the existing climatology evidence that eastern Indo-Gangetic plain receive precipitation mainly from the Bay of Bengal branch of the southwest monsoon. The performance of Bay of Bengal branch during southwest monsoon mainly characterized by formation of low pressure center over the head of Bay of Bengal (Roy and Balling 2004). Annual decreasing trend of total precipitation is well understandable by decreasing trend of categorized rainfall events of categories II and III (heavy and moderate rainfall). This inference is also focused on the subject of global climate change, which might be affected at global and regional scale but at sub regional and micro scale the results could be contrasting.

\section{Conclusions}

The significant long-term trend analysis of extreme rainfall events (1901-2010) were observed over IGP during southwest monsoon. The study shows significant interannual and inter-decadal fluctuation in rainfall frequency and magnitude over the IndoGangetic region. The intensity and occurrence of extreme rainfall events over IGP showed significant decreasing trend for categories II and III (heavy and very heavy rainfall) rainfall events except category I (moderate rainfall) rainfall event, which showed an increasing rainfall frequency. Although trend analysis of extreme rainfall events showed least variation during 1901-2010, it is also found that decrease in frequency of category III rainfall event is more dominant than category II rainfall event. Heavy rainfall occurrence is most probable during July, August and September month of summer monsoon in Gangetic basin (Dhar and Nandargi 2003). The westward shift of the monsoonal pattern and simultaneously weakening of BoB branch may be the possible cause behind the decreasing trend of heavy rainfall events. The trend analysis on monthly scale for the period 1901-2010 shows during withdrawal of Indian summer monsoon event of moderate and heavy rainfall increase, this might contribute in several causes of flood in the region of IGP. In term of distribution and contribution of rainfall in agriculture area categories I and II rainfall events are more important but change in rainfall pattern may lead to flood and drought risk in IGPs. The dry spells and prolonged dry spell remained more or less constant over the 
Indo-Gangetic plain during the period 1901-2010. Short rain events and prolonged rain events both have decreased over Indo-Gangetic plain during the period of study. Maximum rainfall during every epoch of ISM showing decreasing trend except in July and monsoon season.

\section{Acknowledgements}

The authors wish to express sincere thanks to India Meteorological Department for providing the necessary data. One of the authors (AT) acknowledges with thanks the financial assistance in the form of a fellowship provided by the University Grants Commission for research.

\section{References}

Adel M M 2001 Effect on water resources from upstream water diversion in the Ganges basin; J. Environ. Qual. 30 $356-368$.

Adel M M 2002 Man-made climatic changes in the Ganges basin; Int. J. Climatol. 22 993-1016.

Bhatla R and Tripathi A 2014 The study of temperature and rainfall variability over Varanasi; Int. J. Earth Atmos. Sci. 1(2) 90-94.

Bhatla R, Singh M, Mall R K, Tripathi A and Raju P V S 2015 Variability of summer monsoon over Indo-Gangetic plains in relation to El-Nino/La-Nina; Nat. Hazards $\mathbf{7 8}$ 837-853.

Bhatla R, Tripathi A and Singh R S 2016 Analysis of rainfall pattern and extreme events during southwest monsoon season over Varanasi during 1971-2010; Mausam 67(4) 903-912.

Chowdhury M R and Ward N 2004 Hydro-meteorological variability in the greater Ganges-Brahmaputra-Meghna basin; Int. J. Climatol. 24 1495-1508.

Dash S K and Hunt J C R 2007 Variability of climate change in India; Curr. Sci. 93(6) 782-788.

Dash S K, Kulkarni M A, Mohanty U C and Prasad K 2009 Changes in the characteristics of rain events in India; $J$. Geophys. Res. 114 1-12.

Dash S K, Jenamani R K, Kalsi S R and Panda S K 2007 Some evidence of climate change in twentiethcentury India; Clim. Change 85 299-321.

Dhar O N and Nandargi S 2003 Hydrometeorological aspects of floods in India; Nat. Hazards 28 1-33.

Epstein P R 2005 Climate change and human health; New Engl. J. Med. 353 1433-1436.

Gadgil S 2003 The Indian monsoon and its variability; Annu. Rev. Earth Planet. Sci. 31 429-461.

Ghosh S, Luniya V and Gupta A 2009 Trends analysis of Indian summer monsoon rainfall pattern at different spatial scale; Atmos. Sci. Lett. 10 285-290.

Goswami B N, Venugopal V, Sengupta D, Madhusoodanan M S and Xavier P K 2006 Increasing trend of extreme rain events over India in a warming environment; Science $\mathbf{3 1 4}$ 1442-1445.

Guhathakurta P and Menon A P 2011 Impact of climate change on extreme rainfall events and flood risk in India; J. Earth Syst. Sci. 120(3) 359-373.

Guhathakurta P, Rajeevan M, Sikka D R and Tyagi A 2015 Observed changes in southwest monsoon rainfall over India during 1901-2011; Int. J. Climatol. 35 1881-1898.

Jones P D, Raper S C B, Diaz H H, Kelly P M and Wigley T M L 1986 Northern hemisphere surface air temperature variations: 1851-1984; J. Clim. Appl. Meteorol. 25 161179 .

Kendall M G 1975 Rank correlation methods; Griffin, London.

Mann H B 1945 Non-parametric tests against trend; Econometrica 13 245-259.

May W 2004 Variability and extreme of daily rainfall during Indian summer monsoon in the period 1901-1989; Global Planet. Change 44 83-105.

Mohanty M, Ray K and Chakravarthy K 2014 Analysis of increasing heavy rainfall activity over western India, particularly Gujarat state in past decade in high impact weather events over SAARC region; In: High-impact weather events over the $S A A R C$ region (eds) Ray $\mathrm{K}$, Mohapatra M, Bandhopadhyay B K and Rathore L S, Capital Publishing Company, New Delhi, pp. 250-265.

Mohapatra M, Mohanty U C and Behera S 2003 Spatial variability of daily rainfall over Orissa, India, during southwest summer monsoon season; Int. J. Climatol. 23 1867-1887.

Pattanaik D R and Rajeevan M 2010 Variability of extreme rainfall events over India during southwest monsoon season; Meterol. Appl. 17 88-104.

Prasad T and Agrawal A L 1996 A day of exceptionally heavy rainfall over Bombay; Mausam 47(4) 425-428.

Rajeevan M, Bhate J, Kale J D and Lal B 2005 Development of high resolution daily gridded rainfall data for the Indian region; Met. Monogr. Climatol. 22.

Rajeevan M, Bhate J, Kale J D and Lal B 2006 High resolution daily gridded rainfall data for the Indian region: analysis of break and active monsoon spells; Curr. Sci. 91(3) 296-306.

Rajeevan M, Bhate J and Jaswal A K 2008 Analysis of variability and trends of extreme rainfall events over India using 104 years of gridded daily rainfall data; Geophys. Res. Lett. 35 L18707. https://doi.org/10.1029/ 2008 GL035143.

Revadekar J V 2010 Observed trends and model projections of extremes in precipitation and surface temperature over India. PhDThesis, University of Pune, India, pp 180.

Roxy M K, Ritika K, Terray P, Murtugudde R, Ashok K and Goswami B N 2015 Drying of Indian subcontinent by rapid Indian Ocean warming and a weakening landsea thermal gradient; Nat. Comm. 6, https://doi.org/10. 1038/ncomms8423.

Sahai A K, Pattanaik D R, Satyan V and Grimm M A 2003 Teleconnections in recent time and prediction of Indian summer monsoon rainfall; Meteorol. Atmos. Phys. 84 $217-227$.

Sanap S D, Pandithurai G and Manoj M G 2015 On the response of Indian summer monsoon to aerosol forcing in CMIP5 model simulations; Climate Dyn. 45 2949-2961. 
Saseendran S A, Singh K K, Bahadur J and Dhar O N 1995 1 to 10 days extremes rainfall studies for Kerala state; Mausam 46(2) 175-180.

Singh N, Mulye S S and Pant G B 1992a Some features of the arid area variations over India: 1871-1984; Pure Appl. Geophys. 138 135-150.

Singh N, Pant G B and Mulye S S 1992b Spatial variability of aridity over northern India; Proc. Indian Acad. Sci. (Earth Planet. Sci.) 101 201-213.

Sinha R and Jain V 1998 Floods hazards of north Bihar rivers, Indo-Gangetic plains; Mem. Geol. Soc. India 41 $27-52$.

Corresponding editor: KAVIRAJAN RAJENDRAN
Sinha Ray K C and Srivastava A K 2000 Is there any change in extreme events like heavy rainfall?; Curr. Sci. 79(2) $155-158$.

Sonar R B 2014 Observed trend and variations in rainfall events over Ratnagiri (Maharastra) during southwest monsoon season; Mausam 65(2) 171-178.

Srinivasan V, Raman S and Mukherji S 1972 Southwest monsoon-typical situations over West Bengal and Assam and adjacent states; FMU Rep. No. III-3.6, India Meteorological Department.

Thapliyal V and Kulshrestha S M 1991 Climate change and trends over India; Mausam 42 333-338. 